\title{
Modernas metodologias diagnosticas para la detección del Virus del Papiloma Humano y prevención del cáncer de cuello uterino
}

\author{
Modern diagnostic methods for detection of Human \\ Papillomavirus and cervical cancer prevention
}

\author{
Diego F. Rincón R. ${ }^{1}$, Liliana A. Morales L. ${ }^{1}$, Bladimiro Rincón-Orozco ${ }^{1}$
}

Forma de citar: Rincón DF, Morales LA, Rincón Orozco B. Modernas metodologías diagnosticas para la detección del virus del Papiloma Humano y prevención del cáncer de cuello uterino. Rev Univ Ind Santander Salud. 49(3): 478-488.

DOI: http://dx.doi.org/10.18273/revsal.v49n3-2017006 (c) (i)

\section{RESUMEN}

Los Virus del Papiloma Humano (VPH) presentes en mucosa clasificados como de "alto riesgo" son agentes etiológicos de patologías oncológicas como cáncer de cuello uterino, ano, pene, vulva y cáncer orofaríngeo. Actualmente el principal método de tamizaje utilizado en Colombia para detección de cáncer de cuello uterino es la citología cervical, presentando una moderada cobertura en la población femenina y una sensibilidad cercana al $50 \%$. El objetivo de este trabajo es describir las técnicas modernas utilizadas para la detección del VPH y prevención de los cánceres producidos por estos virus. Se llevó a cabo una revisión de literatura de las ultimas metodologías diagnosticas en la infección viral por VPH y marcadores de malignidad en muestras cervicales. La citología cervical es un recurso altamente específico y de bajo costo, pero poco sensible para la detección y prevención de cáncer de cuello uterino, que puede ser complementado con las tecnologías modernas revisadas con el objetivo de obtener un diagnóstico temprano del VPH como agente etiológico de estas enfermedades malignas.

Palabras clave: Virus del Papilloma Humano, diagnóstico molecular, transformación maligna, infección crónica.

\begin{abstract}
Human Papilloma Viruses (HPVs) types present in mucosa and classified as "high risk" are etiologic agents of several oncological diseases as cervical cancer, anus, penis, vulva, and oropharyngeal cancer. Currently the principal method of screening used in Colombia for detecting cervical cancer is cervical cytology, which presents a moderate coverage in the population and sensitivity close to $50 \%$. The objetive of this work is to describe new techniques for detection of Human Papillomavirus and cancer prevention for these viruses. We carried out a literature review of the cutting edge diagnostic methods for HPV viral infection. Cervical cytology is a highly specific resource, low-cost but low sensitivity for preventing cervical cancer, which can be supplemented with the modern technologies checked in order to obtain an early diagnosis of HPV as an etiologic agent of those malignancies.
\end{abstract}

Keywords: Human Papilloma Virus, Molecular diagnosis, malignant transformation, chronic infection.

1. Universidad Industrial de Santander. Bucaramanga, Colombia

Correspondencia: Bladimiro Rincón. Dirección: Escuela de Microbiología, Universidad Industrial de Santander. Correo electrónico: blrincon@ uis.edu.co. Teléfono: +576344000 ext: 3225 . 


\section{DIAGNÓSTICO DEL VIRUS DEL PAPILOMA HUMANO}

El VPH es un virus desnudo con simetría icosaédrica y genoma de doble cadena de ADN que pertenece a la familia Papillomaviridae. Biológicamente se encuentra subdivido en virus presentes en mucosas y en piel (cutáneos) ${ }^{1,2}$. Así mismo, estos virus también pueden dividirse según su riesgo en alto y bajo, en general los virus presentes en mucosa de bajo riesgo (VPH-BR) pueden desarrollar lesiones benignas que no son de importancia clínica (aunque pueden presentar alguna importancia estética), mientras que los virus de alto riesgo (VPH-AR) presentes en mucosas afectan al tracto genital u oral y están involucrados en patologías oncológicas clínicamente relevantes como el cáncer de cuello uterino, ano, pene, vulva y cáncer orofaríngeo ${ }^{3}$.

Los virus de mucosa denominados de alto riesgo (VPHAR) poseen un tropismo por los queratinocitos, estas células se encuentran en la capa basal del cuello uterino y de la mucosa oral ${ }^{1}$. La entrada de estos virus de alto riesgo ocurre principalmente por microlesiones durante las relaciones sexuales, ya que los viriones no poseen la capacidad de infectar el epitelio escamoso intacto.

El proceso de entrada viral ha sido ampliamente discutido ya que no todos los tipos de VPH usan la misma vía de infección ${ }^{4,5}$. La teoría de entrada viral más aceptada involucra un cambio de la proteína L1 que permite la unión del virión a los queratinocitos, este proceso toma varias horas y requiere de tres etapas; como se puede apreciar en la Figura 1, al ingresar a la zona basal, el virión expone la porción $\mathrm{N}$-terminal de la proteína L2 debido a un cambio conformacional de la misma, la cual le permitirá adherirse a los proteoglicanos de heparán sulfato expuestos en la membrana basal del cuello uterino. Luego, se realiza un clivaje de la proteína L2 utilizando una furina celular o una convertasa celular, exponiendo como resultado la molécula de unión con el queratinocito, la cual se presume es la proteína L1 de la cápside viral. Posteriormente, la proteína L1 realiza un cambio de forma que le permite su unión a un receptor que se considera es el complejo integrina $\alpha 6 \beta 4$ en la membrana del queratinocito permitiendo su entrada por medio de mecanismos como endocitosis mediada por clatrina, endocitosis caveolar, endocitosis independiente de clatrina o caveolas ${ }^{4,5}$. Posteriormente el virión infectará a los queratinocitos epiteliales basales, llevando a cabo su proceso de replicación y transformando los queratinocitos en coilocitos (células infectadas), iniciando el proceso de tumorgénesis como se describe en la Figura 2, proceso que puede ser detectado por métodos directos como la citología cervical $^{2,5,6}$.

Adicionalmente, se ha sugerido que la laminina 5 funciona como un receptor en la membrana basal ya que tienen mejor afinidad con el virus que los proteoglicanos de heparán sulfato, sin embargo los proteoglicanos muestran mayor importancia en el proceso de infección ${ }^{7}$. También se ha propuesto que la unión con los queratinocitos no se realiza con un solo receptor celular y que la proteína L2 podría influir en esa unión, lo anterior podría explicar la dificultad de identificar cuáles son las moléculas implicadas en este proceso $^{7}$.

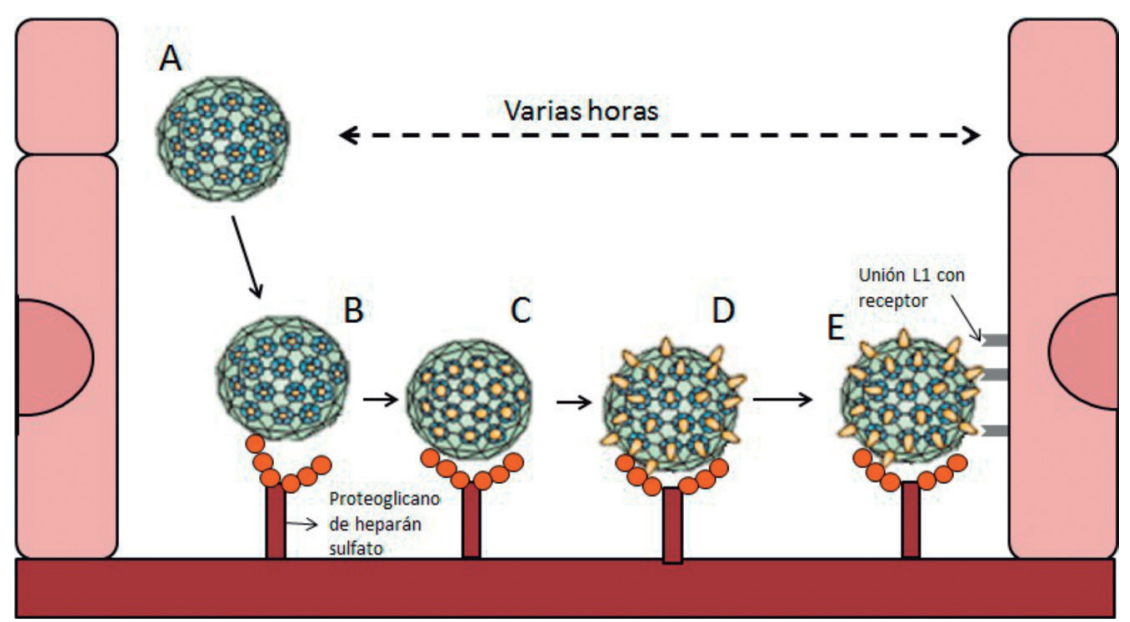

Figura 1. Proceso de infección del virus del papiloma humano en el cuello uterino. Adaptado de Schiller J, et al 5 . A) Entrada del virión a la zona basal del epitelio. B) Unión del virión con los proteoglicanos de heparán sulfato disponibles en la membrana basal. C y D) Cambio conformacional de las proteínas L1 (espículas amarillas) para facilitar su unión al receptor. E) Unión del virión con el queratinocito basal. 


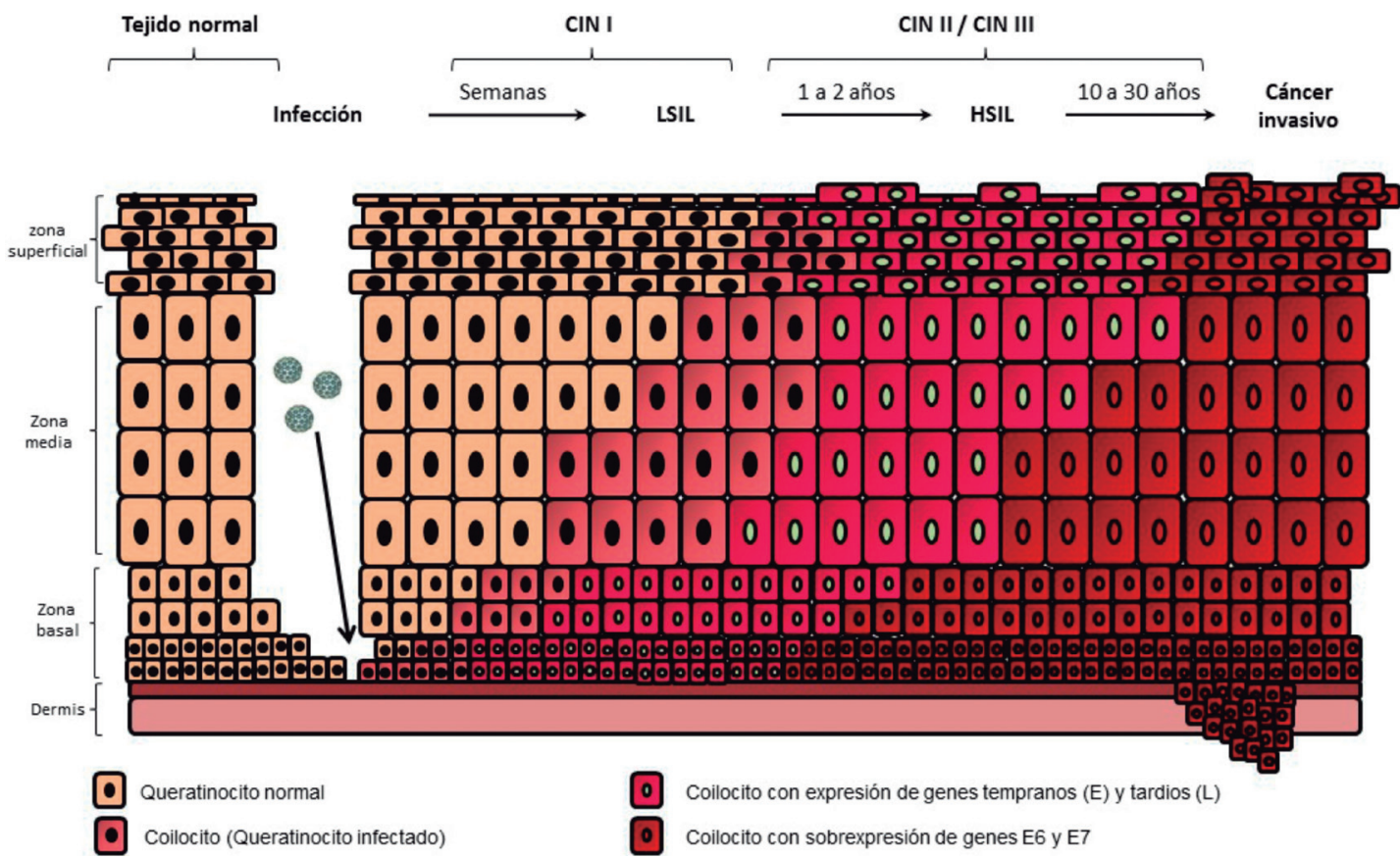

Figura 2. Progresión de la infección viral en el cuello uterino. Adaptado de Roden $\mathrm{R}$, et $\mathrm{al}^{8}$. La zona basal del cuello uterino es infectada por el VPH, el cual empezará a realizar su proceso de replicación e infección en las células adyacentes, durante este proceso el virus realiza la producción de sus proteínas oncogénicas codificadas en sus genes tempranos (E). Posteriormente el virus expresará sus genes tardíos (L) los cuales permiten establecer una infección crónica. A partir de este punto el proceso de carcinogénesis se puede clasificar por medio de la citología cervical como una lesión de bajo grado (LSIL) o CIN 1, la cual puede continuar a una lesión de alto grado (HSIL) o CIN 2/3 luego a cáncer in situ y finalmente terminará infiltrando la membrana basal del cuello uterino convirtiéndose en un cáncer invasivo.

Estadísticamente, el cáncer de cuello uterino es el segundo tipo de cáncer que más muertes causa en la población femenina colombiana, siendo levemente superado por el cáncer de mama $^{9,10}$. Pese a que, estudios epidemiológicos muestran una reducción del $31,8 \%$ en muertes causadas por esta neoplasia cervical entre los periodos de $1984-1988$ y $2004-2008^{10}$, este tipo de cáncer sigue siendo una patología importante para la población femenina y es la razón por la cual es necesario conocer los avances en su tratamiento $\mathrm{y}$ diagnóstico tal y como se ha tratado en trabajos anteriores ${ }^{11}$.

El método de tamizaje actualmente utilizado en Colombia es la citología cervical anual, la cual forma parte del programa de tamizaje para la prevención del cáncer de cuello uterino, este programa cuenta con una cobertura del 76\% según estudios del Instituto Nacional de Salud ${ }^{12}$. Los estudios del Instituto Nacional de Cancerología han mostrado que a pesar del aumento de ejecución de este programa, la mortalidad debido a este tipo de cáncer no ha disminuido en los últimos años, por ejemplo según el Registro de Cáncer de Cali, en el periodo de 1998 a 2002 se registró un ratio de mortalidad: incidencia del 0,44 mientras que el Registro de Cáncer de Manizales registró un ratio del 0,56 para el periodo del 2002 al 2006 ${ }^{10,13,14}$. Según sus estudios, esta situación se debe a diversos factores como la calidad de la toma y lectura de la citología, el tratamiento, la calidad del tratamiento, el acceso oportuno a la confirmación diagnóstica y no solo a la cobertura de la población como lo ha enfocado la $\mathrm{OMS}^{14,15}$. De esta manera, se ha determinado que en Colombia, posiblemente la mayor causa de la mortalidad debido a este tipo de cáncer sea el limitado seguimiento de los casos positivos identificados en la citología cervical, pero también mencionan que debido a la baja sensibilidad de la citología (la cual según sus resultados oscilaba entre 42 y $61 \%)^{13}$ es difícil otorgar un diagnóstico acertado en las pacientes analizadas; por lo que se hace necesario la implementación de nuevas metodologías al programa que tengan una mayor sensibilidad ${ }^{13,16}$.

En la actualidad se buscan métodos complementarios a la citología cervical que contribuyan en el diagnóstico temprano y el direccionamiento hacia el tratamiento adecuado, dentro de los cuales podemos encontrar herramientas diagnósticas de visualización, métodos bioquímicos y métodos de biología molecular los cuales se evidencian en la Tabla 1. 
Tabla 1. Técnicas de diagnóstico para detección de infecciones por Virus del Papiloma Humano

\begin{tabular}{|c|c|c|}
\hline Técnica & Características & Referencia \\
\hline \multicolumn{3}{|c|}{ Herramientas diagnósticas de visualización } \\
\hline $\begin{array}{l}\text { Cámara fotográfica } \\
\text { de alta resolución en } \\
\text { teléfonos inteligentes }\end{array}$ & $\begin{array}{l}\text { Inspección por expertos } \\
\text { usando herramienta de } \\
\text { visualización }\end{array}$ & $(18,17)$ \\
\hline \multicolumn{3}{|l|}{ Métodos bioquímicos } \\
\hline P16INK4a & $\begin{array}{l}\text { Crecimiento celular } \\
\text { incontrolado }\end{array}$ & $(19)$ \\
\hline Ki-67 & $\begin{array}{l}\text { Marcador de crecimiento } \\
\text { tumoral }\end{array}$ & $(19)$ \\
\hline MCM 2 & $\begin{array}{c}\text { Fase S del ciclo celular } \\
\text { aberrante }\end{array}$ & $(19,20)$ \\
\hline TOP2A & $\begin{array}{l}\text { Fase S del ciclo celular } \\
\text { aberrante }\end{array}$ & $(19,20)$ \\
\hline ACTN4 & $\begin{array}{l}\text { Aumento en ciclos } \\
\text { celulares aberrantes }\end{array}$ & $(21)$ \\
\hline \multicolumn{3}{|c|}{ Métodos de Biología Molecular } \\
\hline \multicolumn{3}{|c|}{ Cambios Genéticos } \\
\hline $\begin{array}{l}\text { Cambios } \\
\text { cromosómicos }\end{array}$ & $\begin{array}{l}\text { Pérdidas y ganancias de } \\
\text { brazos cromosómicos } \\
\text { largos y cortos }\end{array}$ & $(19,20)$ \\
\hline microARNs & $\begin{array}{l}\text { Aumento y disminución } \\
\text { para permitir la } \\
\text { carcinogénesis }\end{array}$ & $(22)$ \\
\hline Cambios epigenéticos & $\begin{array}{c}\text { Cambios en la metilación } \\
\text { en el ADN de los } \\
\text { queratinocitos y/o en el } \\
\text { ADN viral durante la } \\
\text { carcinogénesis }\end{array}$ & $(20)$ \\
\hline \multicolumn{3}{|c|}{ Detección de ADN aprobado por la FDA } \\
\hline $\begin{array}{l}\text { Digene Hybrid } \\
\text { Capture } 2\end{array}$ & $\begin{array}{c}\text { Detección de genotipos de } \\
\text { algunos VPH de alto riego } \\
\text { y bajo riesgo }\end{array}$ & $(23,24)$ \\
\hline Cervista HPV HR & $\begin{array}{c}\text { Detección de genotipos de } \\
\text { algunos VPH de alto riesgo } \\
\text { y bajo riesgo }\end{array}$ & $(23,25,26)$ \\
\hline Cervista HPV 16/18 & $\begin{array}{l}\text { Detección de genotipos de } \\
\text { algunos VPH de alto riego } \\
\text { y bajo riesgo }\end{array}$ & $(27)$ \\
\hline Cobas HPV Test & $\begin{array}{l}\text { Detección de genotipos } \\
\text { de algunos VPH de alto } \\
\text { riesgo con identificación } \\
\text { especifica de VPH-16 y } \\
\text { VPH-18 }\end{array}$ & $(15,28)$ \\
\hline \multicolumn{3}{|c|}{ Detección de ARN aprobado por la FDA } \\
\hline Aptima HPV test & $\begin{array}{c}\text { Identificación de RNAm de } \\
\text { E6/E7 del VPH, aprobado } \\
\text { por la FDA }\end{array}$ & $(29,32)$ \\
\hline Aptima HPV 16 18/45 & $\begin{array}{c}\text { Identificación de RNAm } \\
\text { de E6/E7 del VPH, con } \\
\text { identificación especifica de } \\
\text { VPH 16, } 18 \text { y } 45 \text {, aprobado } \\
\text { por la FDA }\end{array}$ & $(23)$ \\
\hline Test comerciales & $\begin{array}{c}193 \text { test para la } \\
\text { identificación del VPH y } \\
\text { al menos } 127 \text { variantes sin } \\
\text { aprobación de la FDA }\end{array}$ & $(31)$ \\
\hline
\end{tabular}

\section{HERRAMIENTAS DIAGNÓSTICAS DE VISUALIZACIÓN}

El uso de las cámaras de alta resolución disponibles en los teléfonos inteligentes, ha permitido la participación de varios expertos de manera simultánea, los cuales están ubicados remotamente pero contribuyen en el diagnóstico y detección de pacientes con lesiones de alto grado conduciéndolas a un mejor tratamiento. Como resultado de esta metodología, los especialistas pueden catalogar las citologías como patológicas, no patológicas e inconclusas ${ }^{18}$. Esta es una metodología relativamente económica y fácilmente asequible basada en la observación del cuello uterino por varios ginecólogos expertos por medio de unas fotografías tomadas por el profesional de la salud que esté realizando la citología y quien además realiza la tinción del cuello uterino con colorantes vitales como ácido acético y lugol yodado; para este proceso se utilizan foros especializados, las cuales permiten tener una opinión experta en un menor tiempo ${ }^{19}$. Esta metodología ha sido aplicada en instituciones de salud ubicadas en regiones apartadas donde el acceso a la salud es escaso pero que cuentan con un observación del cuello uterino básico; condiciones similares a algunas poblaciones del país teniendo por supuesto, un consentimiento previo de la paciente ${ }^{18,19}$.

\section{MÉTODOS BIOQUÍMICOS PARA LA DETECCIÓN Y PREVENCIÓN DEL VPH}

Las proteínas celulares que se expresan durante la infección viral han sido ampliamente estudiadas durante muchos años. En 2010 Schweizer, et al., demostrarón que la detección de la oncoproteína del VPH E6 en muestras cervicales es más específica para detectar lesiones cervicales tipo CIN3 (Cervical Intra-epithelial Neoplasia 3, CIN 3) que la detección de DNA viral para los mismos genotipos ${ }^{33}$. Por otra parte, las técnicas actuales se encaminan a la búsqueda de la sobreexpresión de antígenos como p16INK4a, siendo este un antígeno importante en el área de inmunohistoquímica para el análisis de las lesiones cervicales, p16 es codificado por el gen CDKN2A que interactúa con la proteína $\mathrm{pRb}$, el antígeno p16 bloquea la actividad de la quinasa $\mathrm{CDK} 4 / 6$ que fosforila $\mathrm{pRb}$ y cuando las células están infectadas por VPH-AR, E7 se une a pRb irreversiblemente ${ }^{22}$. En este caso p16 no tiene efecto alguno en la inhibición del ciclo celular y se acumula en el núcleo y citoplasma lo que permite que sea detectado por inmunohistoquímica mostrando una sensibilidad 
del $83 \%$ para detectar estadios iguales o mayores a CIN 2 en atipias de células escamosas de significado incierto (atypical cells of undetermined significance, ASCUS) $\mathrm{y}$ lesiones intraepiteliales escamosas de bajo grado (Low-grade squamous intraepithelial lesión, LSIL), además de una especificidad del $71 \%$ para ASCUS y $65,7 \%$ para LSIL $^{20}$. Actualmente se utiliza el antígeno Ki-67 (marcador del crecimiento tumoral), junto con el p16INK4a permitiendo que aumente su sensibilidad por encima del $90 \%$ además de una especificidad de $80,6 \%$ en ASCUS y $68 \%$ en $\mathrm{LSIL}^{20}$.

Adicionalmente a estos marcadores ampliamente conocidos se suman la proteína 2 para el mantenimiento del minicromosoma 2 (Mini-chromosome maintenance protein 2, MCM 2) esta proteína se encuentra en la cromatina durante la fase G1 y define las ubicaciones potenciales para la iniciación de la replicación del ADN, su deficiencia da como resultado la inestabilidad del genoma $^{34}$. La topoisomerasa alfa II (topoisomerase II alpha, TOP2A) que hace parte de una clase importante de enzimas nucleares responsables del mantenimiento de la topología del ADN y están involucradas en la reparación, la transcripción, la replicación y segregación de los cromosomas ${ }^{35}$ y por último la alfa actina 4 (Alphaactinin-4 ACTN4) es una proteína de unión a actina que participa en la organización del citoesqueleto, esta reside tanto en el citoplasma como en el núcleo y se asocia físicamente con varios factores de transcripción ${ }^{36}$. La elevación de estas proteínas se presenta en las células con fase $\mathrm{S}$ del ciclo celular aberrantes, fase en la cual se evidencia la acción de las proteínas oncogénicas E6 y E7 del VPH ${ }^{20-22}$. Las acciones de estas oncoproteínas han sido ampliamente estudiadas y se ha identificado que son altamente expresadas en células cervicales cancerígenas para mantener su fenotipo tumorigénico. En el caso de la oncoproteína E7 una de sus funciones más importantes es la estimulación del ciclo celular a través de su capacidad para unirse e inactivar la proteína retinoblastoma $(\mathrm{pRb})$. La $\mathrm{pRb}$ es un regulador negativo del ciclo, que normalmente impide la entrada en fase $\mathrm{S}$ mediante la asociación con factores de transcripción; E7 también puede asociarse con otras proteínas implicadas en la proliferación celular, incluyendo las histonas desacetilasas $^{37}$. Por su parte para la oncoproteína E6 uno de los mecanismos de mayor relevancia es la unión a la proteína p53 que conduce a su degradación a través del proteosoma inactivando así, la supresión del crecimiento y/o apoptosis celular mediada por p53, lo anterior permite la acumulación de errores al azar en las células favoreciendo la transformación neoplásica. Estas son, entre otras, las funciones de las oncoproteínas E6 y E7 mejor descritas en la literatura ${ }^{37}$.

Es necesario mencionar que las otras proteínas codificadas en el genoma del virus pueden contribuir a la función de las oncoproteínas mencionadas. E1 y E2 intervienen en la replicación viral, E4 en la desestabilización de la redes de citoqueratina, E5 media señales mitogénicas de factores de crecimiento y transformación temprana, mientras que L1 conforma la proteína mayor de la cápside y L2 la proteína menor ${ }^{1}$.

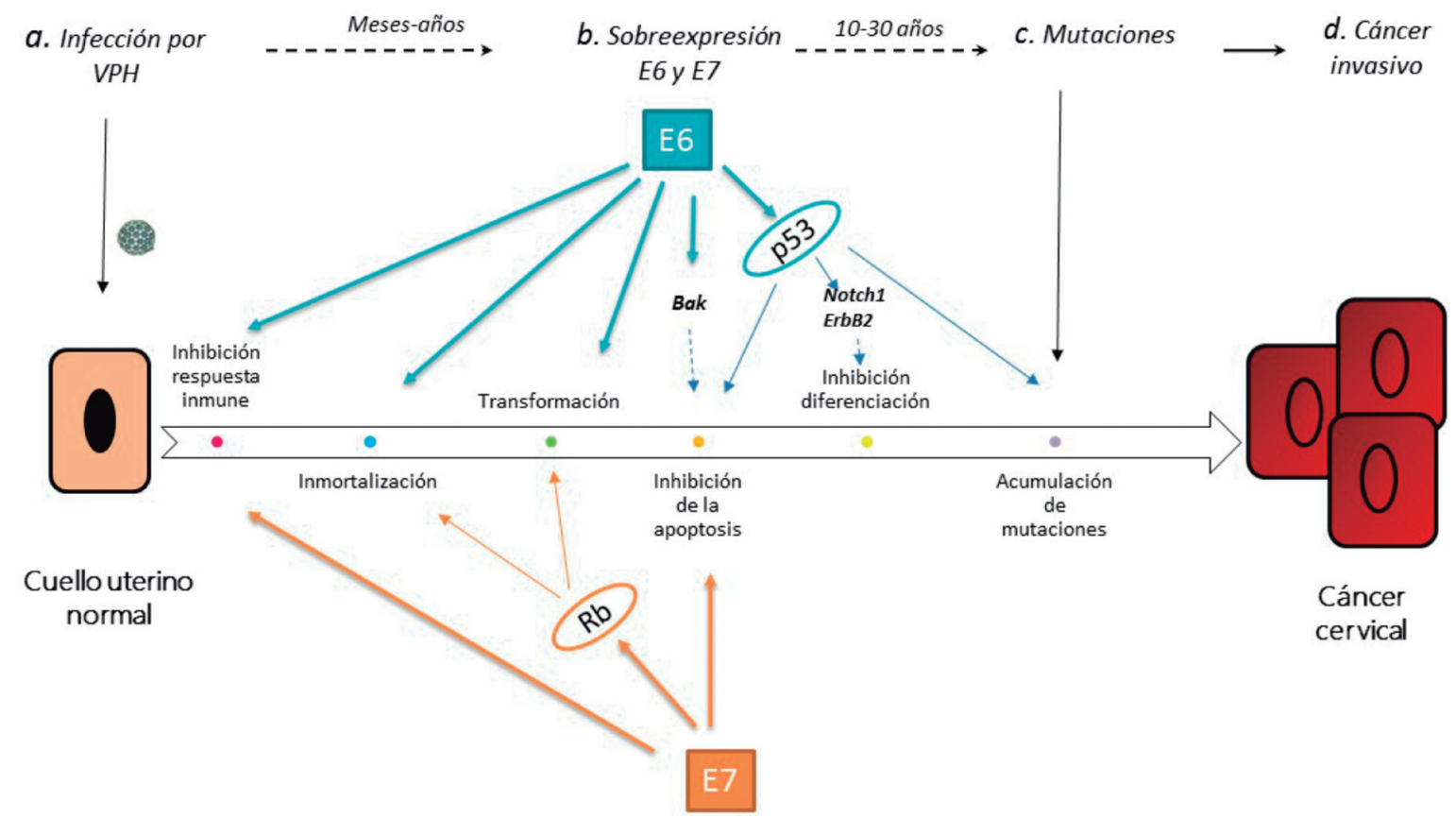

Figura 3. Acción de las oncoproteínas E6 y E7. 


\section{MÉTODOS DE BIOLOGÍA} MOLECULAR PARA LA DETECCIÓN Y PREVENCIÓN DEL VPH

Actualmente, se utilizan marcadores genéticos en los queratinocitos infectados con el VPH como son la ganancia del cromosoma 1q, 3q, 5q, 8q, perdida de $2 \mathrm{q}$, $3 \mathrm{p}, 4 \mathrm{p}, 5 \mathrm{q}, 6 \mathrm{q}, 11 \mathrm{q}, 13 \mathrm{q}$ y $18 \mathrm{q}$, y varios microARNs entre los cuales se encuentran miR-21, miR-126 y miR-143 los cuales tienen un papel importante en el control de la expresión de genes reguladores del ciclo celular y alteración génica, la mayoría de los miRNAs asociados al cáncer de cuello uterino se encuentran en los cromosomas 1, 14, 19 y X, en regiones intrónicas e intergénicas ${ }^{23}$. Además se han identificado cambios epigenéticos como la metilación del ADN del queratinocito infectado por el VPH (proceso que impide la transcripción de genes importantes y ocurre en sitios donde la secuencia de $\mathrm{ADN}$ presenta un alto porcentaje de Citosina y Guanina también llamadas "islas CpG") en los genes SOXI, LMXIA, NKX6-1, WTI, PAXI, DAPK, RASSFI, CDHI, CDKN2A/p16, MGMT, RARB, CADMI, FHIT, TIMP3, TERT, CDHI3, PAXI, TFPI2, CCNA, MAL y TWIST, que codifican en general reguladores negativos del crecimiento celular y la motilidad y se presume que se silencian en las lesiones cancerosas y precancerosas, pero a pesar de mostrar una alta sensibilidad y especificidad no son fácilmente accesibles ${ }^{20,21,23}$. También se ha reportado unos cambios en la metilación de las regiones promotoras de los genes E6, E7 y L1 codificadas en el ADN viral, estos cambios podrían funcionar como marcadores adicionales de cáncer cervical y su progresión ${ }^{21}$. Sin embargo es importante mencionar que a pesar que Poljak M, et al $(2015)^{32}$ informara que en el mercado comercial se encuentran al menos 193 test para la identificación del VPH y al menos 127 variantes de los test originales para agosto del 2015 (En la Tabla 2 se pueden observar algunos de los métodos de genotipificación de ADN y en la Tabla 3 los métodos de detección de ARNm de las oncoproteínas E6/E7), solo seis test moleculares cuentan con la aprobación por la Agencia de Alimentos y Medicamentos o Agencia de Drogas y Alimentos (Food and Drug Administration, FDA) ${ }^{20,38}$.

Tabla 2. Tests de genotipificación completa presentes en el mercado en agosto el año $2015^{32}$

- Ensayos de genotipado completo a base de filtros, bandas o de microtitulación de pocillos de hibridación

- Linear Array HPV Genotyping Test (Roche Molecular Systems Inc)

- INNO-LiPA HPV Genotyping Extra II (Fujirebio)
- RHA Kit SPF10-LiPA25version 1 (Labo Bio-medical Products)

- DNA ELISA Kit HPV SPF10version 1 (Labo Bio-medical Products)

- EasyChip HPV Blot Kit (King Car)

- REBA HPV-ID (Molecules and Diagnostics)

- AmpliQuality HPV-type (AB Analitica) y 3 variantes

- GenoFlow HPV Array Test (DiagCor Bioscience)

- HPV Direct-Flow Chip (Master Diagnostika)

- HPV Easy-Typing Kit (Autoimmun Diagnostika GmbH)

- Full Spectrum HPV Amplification and detection system (GenoID)

- High PapillomaStrip (Operon) y 1 variante

- HPV Genotyping Lateral Flow Array (DiaProbe Inc)

- HPV Genotyping Chip (BioCore)

- GenoFlow HPV array test kit (R2-M) (DiagCor Bioscience)

- AdvanSure HPV GenoBlot Assay (LGLS Diagnostics)

- Genotyping Kit GP (Diassay)

- Human papillomavirus genotyping test kit (PCR-RDB)-19 genotype (Daan Diagnostics) y 1 variante

- Human papillomavirus nucleic acid test kit (PCRFluorescence Probing) - 18 genotype (Daan Diagnostics) y 2 variantes

- DR. HPV-27 Kit (Erba Diagnostics)

- Tests de genotipificación completa basados en electroforesis en gel

- BIOTYPAP Kit (Biotools)

- PCR Human Papillomavirus Typing Set (Takara Bio Inc)

- Human papilloma virus genotyping (Genekam Biotechnology)

- HPV High Risk Typing (Sacace; Nuclear Laser Medicine S.R.L.)

- Tests de genotipificacion completa basados en PCR en tiempo real

- PANA RealTyper HPV Kit (PANAGENE)

- AmpliSens HPV HCR genotype-FRT PCR kit (Federal State Institution of Science)

- Uterine Cervix Cancer of High-risk HPV Genotype Related Real Time PCR Kit (13 Types of HPV Genotypes/2 channels) (Liferiver) y 1 variante

- SuperFast HPV 12 Multiplex Real-time PCR Kit (Kogenebiotech)

- Uterine Cervix Cancer of High-risk HPV Genotype Related Real Time PCR Kit (13 Types of HPV Genotypes/4 channels) (Liferiver) y 1 variante

- HPV genotypes 14 Real-TM Quant (Sacace; Nuclear Laser Medicine S.R.L.) 
- HPV QUANT-15 (HPV 6,11,16,18,31,33,35,39,45,51,52,5 $6,58,59,68$ ) (DNA-Technology LLC) y 1 variante

- Anyplex II HPV HR Detection (Seegene, Seoul, Korea) y 1 variante

- RealBest DNA HPV HR Genotype (JSC "Vector-Best")

- GeneProof Human Papillomavirus (HPV) PCR Kit (GeneProof)

- Tests de genotipificación completa basados en Microarray de media y baja densidad

- PapilloCheck High-risk Test (Greiner Bio-One) y 1 variante

- Clart HPV 2 - Papillomavirus Clinical Arrays (Genomica)

- 21 HPV GenoArray Diagnostic Kit (Hybribio) y 1 variante

- GeneTrack HPV DNA Chip (Genomic Tree)

- GeneSQUARE HPV Microarray (Kurabo Industries)

- Infiniti HPV Genotyping Test (AutoGenomics) y 2 variantes

- PANArray HPV Genotyping Chip (PANAGENE)

- HPVDNAChip (Biomedlab)

- GG HPV Genotyping Chip (GoodGene)

- BMT HPV 9G DNA Kit (Biometrix Technology)

- BMT HPV Genotyping 9G Membrane Kit (Biometrix Technology)

- ProDect Chip HPV Typing kit (Bcs Biotech)

- HPV type 3.5 LCD-Array Kit (Chipron)

- Decipher HPV23genotyping DNA chip (Yaneng Bioscience)

- MyHPV Chip (Mygene Co.)

- EUROArray HPV (EUROIMMUN Medizinische Labordiagnostika AG)

- Tests de genotipificacion completa basados en microesferas

- Multiplex HPV Genotyping Kit (DiaMex)

- LMNX Genotyping kit GP HR (Diassay)

- PapType HR HPV detection and genotyping (Genera Biosystems)

- GENOSEARCH-HPV31 (Medical \& Biological Laboratories)

- Tellgenplex High-risk HPV Genotyping Panel (Tellgen) y 1 variante

- IntelliPlex HPV DNA Genotyping Kit (PlexBio)

- GeneFinder HPV PCR Kit + GeneFinder HPV Liquid Beads MicroArray Genotyping Kit (Infopia)

- HPV 27 Genotyping Test Kit (Tellgen Corporation)

- Mebgen HPV kit (Medical \& Biological Laboratories)

- Tests de genotipificacion completa basados en electroforesis capilar

- f-HPV typing (Genomed Diagnostics; Molgentix)
- SureX HPV 25X Genotyping Kit (Health Gene Technologies Co. Ltd.)

- HPV HR Detection Test (Trovagene, Inc.)

- Tests de genotipificación completa basados en PCR combinada con matriz asistida por láser de desorción / espectrometría de ionización de tiempo de vuelo total

- HPV MassArray (BGI Americas Corporation)

- PapilloTyper (GeneMatrix Co.)

- Tests de genotipificación completa basados en PCR combinada con secuenciación

- GTPlex HPV PyroSeq Test (Genomic Tree)

- HPV Type-Detect 3.0 by Next Generation Sequencing (Reflex to HPV-16 Risk Assessment Status) (Medical Diagnostic Laboratories) y 1 variante

- HPV sign Genotyping Test (Qiagen Gaithersburg, Inc.)

- Tests de genotipificación completa basados en la amplificación isotérmica mediada por bucle y chip de ADN electroquímico

- Clinichip HPV (Sekisui Medical)

Tabla 3. Tests de HPV-AR para el ARNm de las oncoproteínas E6/E7 presentes en el mercado en agosto el año $2015^{32}$

- Identificación de HPV-AR ARNm de las oncoproteínas E6/ E7

- APTIMA HPV assay (Hologic) y 1 variante

- PreTect HPV-Proofer HV (NorChip)

- NucliSENS EasyQ HPV (Biomerieux)

- QuantiVirus HPV E6/E7 mRNA for Cervical Cancer (DiaCarta LLC)

- FLOWSCRIPT HPV E6/E7 assay kit (Enzo Life Sciences)

- PreTect SEE (NorChip)

- CervicGen HPV RT-qDX (Optipharm)

- CervicGen hTERT RT-qDX (Optipharm)

- QuantiVirus HPV E6/E7 mRNA for Head-Neck Cancer (DiaCarta LLC)

Estos seis métodos aprobados por la FDA se dividen en cuatro métodos de determinación del ADN viral (Digene Hybrid Capture 2 (HC2) high-risk HPV DNA test; Cervista HPV HR and Genfind DNA Extraction Kit; Cervista HPV 16/18 y Cobas HPV Test y dos métodos de determinación de ARN viral (Aptima HPV assay y su variación Aptima HPV 16 18/45 genotype assay $)^{37}$.

Hybrid Capture 2: producido por Qiagen ${ }^{\circledR}$ y aprobado por la FDA en el $2003^{24}$. Es una técnica que utiliza una fase liquida que permite la hibridación por complementariedad del ADN viral con el ARN sintético 
de 13 genotipos de VPH-AR $(16,18,31,33,35,39,45$, $51,52,56,58,59$ y 68$)$ y cinco $\operatorname{VPH}-\mathrm{BR}(6,11,42,43$ y 44). La hibridación es captada por anticuerpos fijados en los pozos de la microplaca, se elimina el exceso de reactivos, se agrega un revelador luminiscente y la emisión de luz es proporcional a la cantidad de ADN, otorgando una medida semicuantitativa de la carga viral $^{25}$.

Cervista HPV HR and Genfind DNA Extraction Kit: realizado por Hologic $\AA$ y aprobado por la FDA en el $2009^{24}$. Permite detectar por reacción cruzada a VPH 66 además de los capturados por Hybrid Capture 2. Posee el mismo procedimiento ya descrito ${ }^{26,27}$.

Cervista HPV 16/18: hecho también por Hologic $\AA$ y aprobado el mismo año (2009) fue diseñado para la identificación específica de los genotipos VPH 16 y VPH $18^{24}$.

Cobas HPV Test: fabricado por Roche Molecular Systems ${ }^{\circledR}$ y aprobado por la FDA en el $2014^{25}$. Tiene la capacidad de detectar 12 genotipos de VPH-AR $(31,33$, $35,39,45,51,52,56,58,59,66$ y 68) además de una identificación específica de los genotipos 16 y 18 con la ayuda de unos cebadores específicos para la $\beta$-globina. Se realiza por medio de una PCR en tiempo real con una amplificación detectada por fluorocromos, uno para las secuencias de los 12 VPH-AR y otros diferentes para 16,18 y $\beta$-globina ${ }^{16,29}$.

Mientras que la detección del ARN viral cuenta actualmente con:

Aptima HPV assay: aprobada por la FDA en el $2012^{24}$, manufacturado por Hologic Gen-Probe $\AA$, identifica 14 VPH-AR mediante una PCR en tiempo real $(16,18$, $31,33,35,39,45,51,52,56,58,59,66$ y 68) en tres procesos: Primero una identificación de la secuencia de trabajo. Segundo, una amplificación mediada por transcripción utilizando la enzima RNA polimerasa, las cuales permitirán una mayor cantidad de copias de ARN, posteriormente la enzima RNA transcriptasa reversa realiza un cambio de ARN a ADNc (ADN complementario). Finalmente se realiza una PCR en tiempo real que permite la detección y posible cuantificación de la amplificación en forma de ADNc obtenido, utilizando colorantes específicos de ácidos nucleicos de doble cadena ${ }^{30,33}$. Algunos autores han propuesto que este método podría permitir identificar a las pacientes que teniendo el diagnóstico de CIN 2 causado por un tipo de VPH-AR, desarrollarían un carcinoma escamocelular o un adenocarcinoma, pero otros autores no han observado estos resultados por lo que aun este es un tema controversial y requiere una mayor investigación al respecto ${ }^{39}$.

Aptima HPV 16 18/45 genotype assay: es una variación del Aptima HPV assay que permite la amplificación, cuantificación y genotipificación del ARNm de las oncoproteínas E6/E7 de los tipo de VPH 16,18 y $45^{28}$. Tiene la posibilidad de diferenciar los tipos VPH 16 de VPH 18 o de VPH 45 pero no permite la diferenciación de VPH 18 de VPH 45. El principio de la técnica es similar al anterior con la diferencia que el ARN es tomado por microparticulas magnéticas que contienen oligomeros de captura los cuales contienen secuencias especificas complementarias y cadenas de residuos de desoxiadenosina que permiten la unión del ARNm. Durante la fase de hibridación, la región desoxiadenosina del oligómero de captura y el polidesoxitimidina se unen covalentemente a las partículas magnéticas, las cuales son posteriormente retiradas del sobrenadante utilizando magnetos, separándolas del material genético para luego continuar con su transformación a $\mathrm{ADNc}^{28}$.

\section{CONCLUSIÓN}

La citología cervical es un recurso altamente específico y de bajo costo pero poco sensible para la detección de lesiones pre-malignas o cáncer de cuello uterino, esta debilidad puede ser superada complementando la citología cervical tradicional con tecnologías modernas que permitan detectar e identificar la presencia y actividad de los VPH-AR presentes en mucosa cervical para poder asociar este hallazgo junto a cambios morfológicos anormales presente en queratinocitos del cuello uterino indicativos de iniciación o presencia de la enfermedad maligna.

Debido a esto, se propone los siguientes flujogramas de diagnóstico que permiten incluir estas nuevas tecnologías al esquema de diagnóstico y seguimiento de estos casos utilizado actualmente en el país, haciendo una diferencia entre los países de altos ingresos y países de bajos ingresos ${ }^{12,40}$. Es preciso recordar que estos métodos requieren ser estudiados en la población donde se quieren aplicar y determinar las ventajas y desventajas que se pueden presentar al agregarlos al esquema de diagnóstico actual ver Figuras 4 y 5, además se recomienda continuar las campañas de cobertura de la población femenina colombiana con el fin de detectar a tiempo estas lesiones malignas y así favorecer una mejor calidad de vida e esta población ${ }^{10}$. 


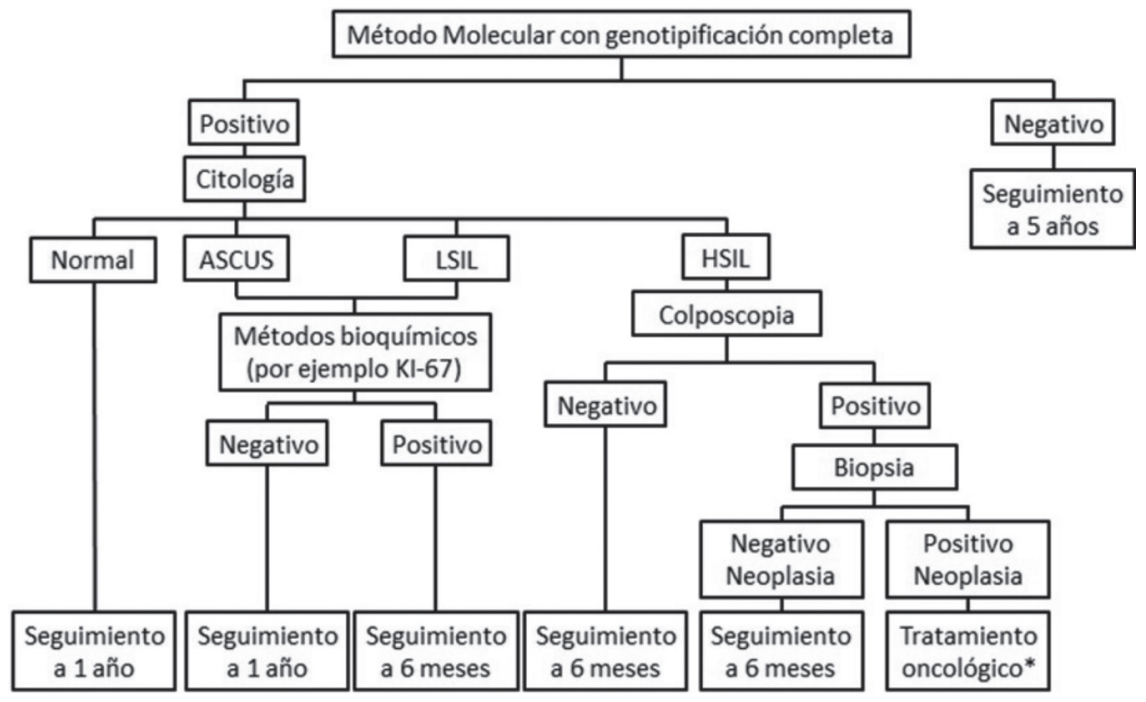

Figura 4. Propuesta de flujograma para la detección y diagnóstico de cáncer de cuello uterino en países de altos ingresos. (*) El tratamiento depende directamente de las características del paciente y se debe realizar un control del tratamiento con una prueba molecular de VPH.

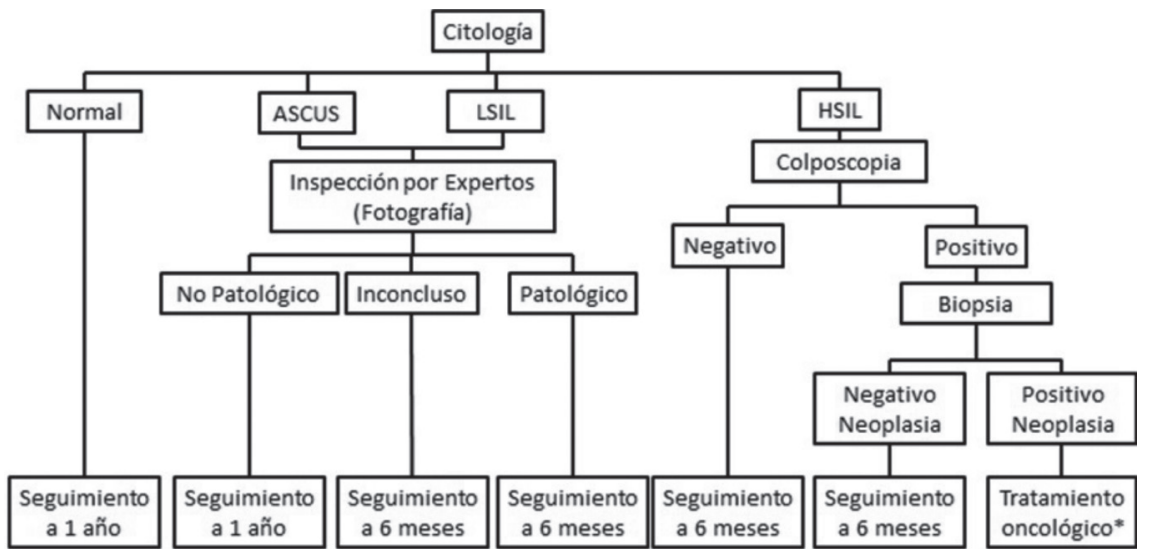

Figura 5. Propuesta de flujograma para la detección y diagnóstico de cáncer de cuello uterino en países de bajos ingresos. (*) El tratamiento depende directamente de las características del paciente.

\section{REFERENCIAS}

1. Ghittoni R, Accardi R, Chiocca S, Tommasino M. Role of human papillomaviruses in carcinogenesis. Ecancermedicalscience. 2015; 9(526): 1-9. DOI: 10.3332/ecancer.2015.526.

2. Moerman-herzog A, Nakagawa M. Early defensive mechanisms against human papillomavirus infection. Clin Vaccine Immunol. 2015; 22(8): 850857. DOI: 10.1128/CVI.00223-15.

3. Egawa N, Egawa K, Griffin H, Doorbar J. human papillomaviruses; epithelial tropisms, and the development of neoplasia. Viruses. 2015; 7(7): 3863-3890. DOI: 10.3390/v7072802.

4. Letian T, Tianyu Z. Cellular receptor binding and entry of human papillomavirus. Virol J. 2010; 7: 2. DOI: $10.1186 / 1743-422 X-7-2$.
5. Schiller JT, Lowy DR. Understanding and learning from the success of prophylactic human papillomavirus vaccines. Nat Rev Microbiol. 2012; 10(10): 681-692. DOI: 10.1038/nrmicro2872.

6. Sana DE, Mayrink de Miranda P, Pitol BC, Moran MS, Silva NN, Guerreiro da Silva ID, et al. Morphometric evaluation and nonclassical criteria for the diagnosis of HPV infection and cytological atypia in cervical samples. Diagn Cytopathol. 2013;41(9). 785-792. DOI: 10.1002/dc.22955.

7. Horvath C a J, Boulet G a V, Renoux VM, Delvenne PO, Bogers J-PJ. Mechanisms of cell entry by human papillomaviruses: an overview. Virol J. 2010; 7:11. DOI: 10.1186/1743-422X-7-11.

8. Roden R, Wu T-C. How will HPV vaccines affect cervical cancer?. Nat Rev Cancer. 2006; 6(10): 753763. DOI: $10.1038 / \mathrm{nrc} 1973$ 
9. Piñeros M, Gamboa O, Hernández-Suárez G, Pardo C, Bray F. Patterns and trends in cancer mortality in Colombia 1984-2008. Cancer Epidemiol. 2013; 37(3): 233-239. DOI: 10.1016/j.canep.2013.02.003.

10. Cendales R, Pardo C, Uribe C, Lopez G, Yepez MC, Bravo LE. Data quality at population-based cancer registries in Colombia. Biomedica. 2012; 32(4): 536544. DOI: $10.1590 / \mathrm{S} 0120-41572012000400009$.

11. Morales LA, Rincón DF, Rincón-Orozco B. Avances en el desarrollo de nuevas vacunas profilácticas y terapéuticas contra el Virus del Papiloma Humano. Rev Univ Ind Santander Salud. 2016; 48(3): 385391. DOI: http://dx.doi.org/10.18273/revsal.v48n32016012.

12. INSTITUTO NACIONAL DE SALUD. Protocolo de vigilancia en salud publica cancer de mama y cuello uterino. República de Colombia, Ministerio de Salud. V02- 05-01 2016

13. Murillo R, Wiesner C, Cendales R. Comprehensive evaluation of cervical cancer screening programs : the case of Colombia. Salud Publica Mex. 2011; 53(6): 469-478.

14. Murillo R, Cendales R, Wiesner C, Piñeros M, Tovar $\mathrm{S}$. Efectividad de la citología cérvico-uterina para la detección temprana de cáncer de cuello uterino en el marco del sistema de salud de Colombia. Biomédica. 2009; 29(3): 344-351. DOI: http:// dx.doi.org/10.7705/biomedica.v29i3.7.

15. Lucumí D, Gómez L. Accesibilidad a los servicios de salud en la práctica de citología reciente de cuello uterino en una zona urbana de Colombia. Rev Esp Salud Pública. 2004; 78: 367-377.

16. Agorastos T, Chatzistamatiou K, Katsamagkas T, Koliopoulos G, Daponte A, Constantinidis T, et al. Primary Screening for cervical cancer based on highrisk human papillomavirus (HPV) Detection and HPV 16 and HPV 18 Genotyping, in Comparison to Cytology. PLoS One. 2015; 10(3): e0119755. DOI: 10.1371/journal.pone.0119755.

17. Comparetto C, Borruto F. Cervical cancer screening: a never-ending developing program. World J Clin cases. 2015; 3(7): 614-624. DOI: 10.12998/wjcc. v3.i7.614.

18. Quinley K, Gormley R, Ratcliffe S, Shih T, Szep $\mathrm{Z}$, Steiner A, et al. Use of mobile telemedicine for cervical cancer screening. J Telemed Telecare. 2011; 17(4): 203-209. DOI: 10.1258/jtt.2011.101008.

19. Ricard-Gauthier D, Wisniak A, Catarino R, van Rossum AF, Meyer-Hamme U, Negulescu R, et al. Use of smartphones as adjuvant tools for cervical cancer screening in low-resource settings. J Low Genit Tract Dis. 2015; 19(4): 295-300.

20. Tornesello ML, Buonaguro L, Giorgi-Rossi P,
Buonaguro FM. Viral and cellular biomarkers in the diagnosis of cervical intraepithelial neoplasia and cancer. Biomed Res Int. 2013; 2013: 519619. DOI: http://dx.doi.org/10.1155/2013/519619.

21. Sahasrabuddhe V, Luhn P, Wentzensen N. Human papillomavirus and cervical cancer: biomarkers for improved prevention efforts. Future Microbiol. 2011; 6(9): 1-25. DOI: 10.2217/fmb.11.87.

22. Van Raemdonck GAA, Tjalma WAA, Coen EP, Depuydt CE, Van Ostade XWM. Identification of protein biomarkers for cervical cancer using human cervicovaginal fluid. PLoS One. 2014; 9(9): e106488. DOI: https://doi.org/10.1371/journal. pone.0106488.

23. Banno K, Iida M, Yanokura M, Kisu I, Iwata T, Tominaga E, et al. MicroRNA in Cervical Cancer: OncomiRs and tumor suppressor miRs in diagnosis and treatment. Sci World J. Hindawi Publishing Corporation; 2014;2014:8. DOI: http://dx.doi. org/10.1155/2014/178075

24. Goodman A. HPV testing as a screen for cervical cancer. Bmj. 2015; 350: h2372-h2372. DOI: https:// doi.org/10.1136/bmj.h2372.

25. Chan PKS, Picconi MA, Cheung TH, Giovannelli L, Park JS. Laboratory and clinical aspects of human papillomavirus testing. Crit Rev Clin Lab Sci. 2012; 49(4): 117-136. DOI: 10.3109/10408363.2012.707174.

26. Alameda F, Garrote L, Mojal S, Sousa C, Muset M, LLoveras B, et al. Cervista HPV HR test for cervical cancer screening a comparative study in the catalonian population. Arch Pathol Lab Med. 2015; 139(2): 241-244. DOI: 10.5858/arpa.2014-0012OA84921465153\&partnerID $=40 \&$ md5 $=6389 a 981$ 04d21da764bd932fed1edd5d.

27. Youens KE, Hosler G a., Washington PJ, Jenevein EP, Murphy KM. Clinical Experience with the Cervista HPV HR Assay. J Mol Diagnostics. Elsevier Inc.; 2011; 13(2): 160-166. DOI: 10.1016/j. jmoldx.2010.11.016.

28. HOLOGIC. Aptima HPV 16 18/45 Genotype Assay. AW-12821 Rev. 001. 2007-2015.

29. Paes EF, de Assis AM, Teixeira CSC, Aoki FH, Teixeira JC. Development of a multiplex PCR Test with automated genotyping targeting e7 for detection of six high-risk human papillomaviruses. PLoS One. 2015; 10(6): e0130226. DOI: https://doi. org/10.1371/journal.pone.0130226.

30. Wang H-Y, Park S, Kim S, Lee D, Kim G, Kim Y, et al. Use of hTERT and HPV E6/E7 mRNA RT-qPCR TaqMan Assays in combination for diagnosing highgrade cervical lesions and malignant tumors. Am J Clin Pathol. 2015; 143(3): 344-351. DOI: 10.1309/ 
AJCPF2XGZ2XIQYQX.

31. Origoni M, Cristoforoni P, Carminati G, Stefani C, Costa S, Sandri MT, et al. E6/E7 mRNA testing for human papilloma virus-induced high-grade cervical intraepithelial disease (CIN2/CIN3): a promising perspective. Ecancermedicalscience. 2015; 9: 533. DOI: 10.3332/ecancer.2015.533.

32. Poljak M, Kocjan Bostjan J, Ostrbenk A, Seme K. Commercially available molecular tests for human papillomaviruses (HPV): 2015 update. J Clin Virol. 2016;76 (Suppl 1): S3-S13. DOI: 10.1016/j. jev.2015.10.023.

33. Schweizer J, Lu PS, Mahoney CW, Berard-BErgery M, Ho M, Ramasamy V, et al. Feasibility Study of a Human Papillomavirus E6 Oncoprotein Test for Diagnosis of Cervical Precancer and cancer. 2010; 48(12): 4646-4648. DOI: 10.1128/JCM.01315-10.

34. Kunnev D, Freeland A, Qin M, Leach RW, Wang J, Shenoy RM, Pruitt SC. Effect of minichromosome maintenance protein 2 deficiency on the locations of DNA replication origins. Genome Res. 2015; 25(4): 558-569. DOI: 10.1101/gr.176099.114.

35. Kumar A, Ehrenshaft M, Tokar E, Mason R, Sinha B. Nitric oxide inhibits topoisomerase II activity and induces resistance to topoisomerase II-poisons in human tumor cells. Biochimica et Biophysica Acta (BBA) - General Subjects.2016; 1860(7): 1519-1527. DOI: http://dx.doi.org/10.1016/j. bbagen.2016.04.009.

36. Aksenova V, Turoverova L, Khotin M, et al. Actinbinding protein alpha-actinin 4 (ACTN4) is a transcriptional co-activator of RelA/p65 sub-unit of NF-kB. Oncotarget. 2013; 4(2): 362-372.

37. Wang H, Park S, Lee D, Kim S, Kim G, Hwa K, et al. Prevalence of type-specific oncogenic human papillomavirus infection assessed by HPV E6 / E7 mRNA among women with high-grade cervical lesions. Int J Infect Dis. 2015; 37: 135-142. DOI: 10.1016/j.ijid.2015.06.018.

38. U.S. Food and Drug Administration. Devices@ FDA.

39. Persson M, Wendel S, Ljungblad L, Johansson B, Weiderpass E, Andersson S. High-risk human papillomavirus E6/E7 mRNA and L1 DNA as markers of residual/recurrent cervical intraepithelial neoplasia. Oncol Rep. 2012; 28(1): 346-352. DOI: 10.3892/or.2012.1755.

40. INSTITUTO NACIONAL DE SALUD. Norma técnica para la detección temprana del cáncer de cuello uterino y guía de atención de lesiones preneoplásicas de cuello uterino. República de Colombia, Ministerio de Salud. Imprenta Nacional de Colombia. 2000; 44-48. 